\title{
Development of high damping natural rubber/butyl rubber composites compatibilized by isobutylene-isoprene block copolymer for isolation bearing
}

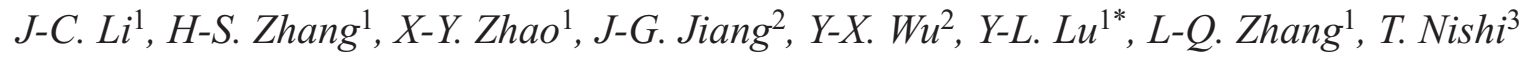 \\ ${ }^{1}$ State Key Laboratory of Organic-Inorganic Composites, Beijing University of Chemical Technology, 100029 Beijing, \\ China \\ ${ }^{2}$ State Key Laboratory of Chemical Resource Engineering, Beijing University of Chemical Technology, 100029 Beijing, \\ China \\ ${ }^{3}$ International Department, Tokyo Institute of Technology, 2-12-1 O-okayama, Meguro-ku, 152-8552 Tokyo, Japan
}

Received 3 December 2018; accepted in revised form 9 March 2019

\begin{abstract}
Natural rubber (NR) and butyl rubber (IIR) blends were compatibilized by isobutylene-isoprene block copolymer (IIBC) which was specifically synthesized with a relatively high content of isoprene (14.5\% mole fraction). Aiming at high damping elastomers, the IIR acts as the high damping phase dispersed in the natural rubber (NR) matrix in this blend. The morphology and microstructure was characterized by atomic force microscope (AFM) and transmission electron microscope (TEM). The results indicated that the IIBC as a compatibilizer could greatly increase the interfacial thickness. Damping property was studied by dynamic mechanical thermal analyzer (DMTA) and rubber processing analyzer (RPA). The results showed that the loss factor greatly increased with adding IIBC, and this may be due to the improved stress transfer promoting the IIR phase to deform and then dissipate energy. The tensile test demonstrated that the tensile strength and modulus increased when 4 parts per hundred rubber [phr] of IIBC was added. Finally, the NR and new NR/IIR isolation bearing samples were prepared and tested on a pressure shear testing machine that could simulate the actual situation during an earthquake. The results showed that hysteretic loss (for one cycle) of the new NR/IIR sample is $83 \%$ higher than that of the NR sample, rendering the compatibilized blends potential in isolation rubber bearings application.
\end{abstract}

Keywords: polymer blends and alloys, natural rubber, butyl rubber, damping property, isobutylene-isoprene block copolymer

\section{Introduction}

As a highly unexpected and unpredictable natural disaster, earthquakes seriously did damage to human lives and properties. Destruction of the buildings is the most direct cause of casualties and economic losses during the earthquake. Isolation bearing is an important device to reduce the seismic force transmitted to buildings with functions of restoring force and energy dissipation. Usually the isolation bearings are set between the foundation and the building structure to increases the structure deformability and hysteretic damping ability of buildings thereby protecting life and reducing economic loss [1-3]. Excellent damping performance is a prerequisite for the isolation bearing materials. In addition, the materials used for isolation bearings must have a good overall performance, such as high strength to resist damage [4, 5]. Natural rubber (NR) is known to exhibit numerous outstanding properties such as desirable physical and mechanical properties, good processing properties, and excellent flexibility, and is an indispensable material for industrial applications. Especially, the crystallization of NR can increase its tensile strength and ability to resist damage [6-9]. However, because of 
the flexible and nonpolar macromolecular chains of $\mathrm{NR}$, internal friction among the NR chains is very weak. Therefore, NR has a quite poor damping performance, which greatly limits its application in the field of anti-seismic materials $[10,11]$. Thus, improving the damping property of natural rubber is of significance.

Butyl rubber (IIR) is a linear copolymer of isoprene (mole fraction typically less than 3\%) and isobutylene. Comparing to any other polymers, IIR, due to the chain backbone densely distributed with a large number of methyl side groups, shows a relatively high damping peak height and broad damping temperature range $[12,13]$. Generally, the blending of two or more types of rubbers is a useful and important way for the preparation and development of rubber blends with properties superior to those of individual constituents [14-16]. Considering the large loss factor of IIR, the introduction of IIR into NR should be an effective way to improve the damping property of NR. In this blends, the IIR is acting as damping phase to provide the damping property needed in dissipating seismic energy, while the NR matrix is to provide the high strength needed in large deformations. However, NR/IIR blends are immiscible and usually exhibit phase separated morphology and poor interfacial adhesion between the phases. Therefore, it is necessary to introduce an interfacial compatibilizer to the binary system to improve the total performance.

In this study, NR/IIR blends were prepared for high damping applications. We specially synthesized an isobutylene-isoprene block copolymer (IIBC) with relatively high content of isoprene $(14.5 \%$ mole fraction) to act as the compatibilizer of NR/IIR blends. The morphological, structural, and mechanical properties of the NR/IIR blends were systematically investigated. The results indicated that the IIBC as a compatibilizer could greatly increase the interfacial thickness. Compared with NR/IIR blend, the compatibilized NR/IIR blends exhibited higher performance, especially a higher damping factor. Finally, the $\mathrm{NR}$ and new NR/IIR isolation bearing samples were prepared and tested on a pressure shear testing machine that could simulate the actual situation during an earthquake. All properties of the new NR/IIR sample meet the requirements of the standard (Chinese Standard JG-118-2019). The hysteretic loss (for one cycle) of the new NR/IIR sample is $83 \%$ higher than that of the NR sample.

\section{Experimental}

\subsection{Materials}

NR (ribbed smoked sheet No.1) was supplied by Nanjing Shengdong Chemical Co., Ltd. (Nanjing, China). IIR (301) was purchased from Polysar Co., Ltd. (Canada). IIBC was synthesized with a relatively high content of isoprene (14.5\% mole fraction) by cationic polymerization. Other chemicals and ingredients were standard industrial grades used for rubber compounding and purchased in China. All materials were used without further purification.

\subsection{Sample preparation}

1. Synthesis of IIBC: Polymerizations were carried out in reaction bottles under dry nitrogen at $-80^{\circ} \mathrm{C}$. $n$-hexane-dichloromethane mixture $(60: 40 \mathrm{v} / \mathrm{v})$, isobutene (IB) and initiator were transferred to pre-chilled reaction bottle. Then the reaction was started by the addition of the chilled solution of ferric trichloride-isopropanol mixture (1.4:1 molar ratio) in $\mathrm{CH}_{2} \mathrm{Cl}_{2}$ with syringes. After stirring for $10 \mathrm{~min}$, isoprene (IP) was added. The reactions were quenched by the injection of ethyl alcoholwater mixtures $(1: 1 \mathrm{v} / \mathrm{v})$. The reaction mixtures were repeatedly diluted and washed with n-hexane and ethyl alcohol. The polymers were dried in vacuum at $40^{\circ} \mathrm{C}$ until constant weight was obtained.

2. IIR compound: The as-received IIR and IIBC were mixed and kneaded with mass ratios of 10/0, 10/2, $10 / 4,10 / 6$ on a $\Phi 152.4 \mathrm{~mm}$ two-roll mill at room temperature for $3 \mathrm{~min}$. Then each compound was blended with compounding and crosslinking additives, including 4.0 parts per hundred rubber [phr] of zinc oxide, $2.0 \mathrm{phr}$ of stearic acid, $1.0 \mathrm{phr}$ of accelerant TMTD (Tetra-methylthiuram disulfide), $0.6 \mathrm{phr}$ of accelerant M (2-Mercaptobenzothiazole), $2.0 \mathrm{phr}$ of sulfur, and $8.0 \mathrm{phr}$ of naphthenic oil. Each compound was then kneaded on the two-roll mill at room temperature for $5 \mathrm{~min}$ to form the IIR compound.

3. NR compound: The as-received NR was kneaded on a two-roll mill at room temperature for $3 \mathrm{~min}$ and then blended with compounding and crosslinking additives, including $3.0 \mathrm{phr}$ of zinc oxide, $1.0 \mathrm{phr}$ of stearic acid, $1.2 \mathrm{phr}$ of accelerant CZ ( $N$ cyclohexyl-2-benzothiazole sulfonamide), $0.2 \mathrm{phr}$ of accelerant TMTD, $1 \mathrm{phr}$ of sulfur, $2 \mathrm{phr}$ of antioxidant 4010NA (1, 4-Benzenediamine). The 
Table 1. Recipes of NR/IIR composites (Unit: Parts per hundred rubber $[\mathrm{phr}])$.

\begin{tabular}{|c|c|c|c|c|}
\hline $\begin{array}{c}\text { Components } \\
\text { [phr] }\end{array}$ & 1\# & 2\# & $3 \#$ & 4\# \\
\hline NR & \multicolumn{4}{|c|}{80} \\
\hline IIR & \multicolumn{4}{|c|}{20} \\
\hline IIBC & 0 & 4 & 8 & 12 \\
\hline Zinc oxide & \multicolumn{4}{|c|}{3.2} \\
\hline Stearic acid & \multicolumn{4}{|c|}{1.2} \\
\hline $4010 \mathrm{NA}$ & \multicolumn{4}{|c|}{1.6} \\
\hline $\mathrm{CZ}$ & \multicolumn{4}{|c|}{0.96} \\
\hline TMTD & \multicolumn{4}{|c|}{0.36} \\
\hline $\mathrm{M}$ & \multicolumn{4}{|c|}{0.12} \\
\hline Sulfur & \multicolumn{4}{|c|}{1.2} \\
\hline Naphthenic oil & \multicolumn{4}{|c|}{1.6} \\
\hline
\end{tabular}

mixture was then kneaded on the two-roll mill at room temperature for $5 \mathrm{~min}$ to form the NR compound.

4. NR/IIR/IIBC composites: The NR compound and IIR compound were kneaded with mass ratios of $80 / 20,80 / 24,80 / 28,80 / 32$ to form the NR/IIR/ IIBC (80/20/0), NR/IIR/IIBC (80/20/4), NR/IIR/ IIBC (80/20/8), NR/IIR/IIBC (80/20/12), composites on a two-roll mill at room temperature for $5 \mathrm{~min}$ (The specific ingredients of the recipes are shown in Table 1). These mixtures were then hot pressed and vulcanized at $145^{\circ} \mathrm{C}$ under a pressure of $15 \mathrm{MPa}$ for varied periods of time as determined by a disc rheometer. The NR/IIR/IIBC composites were obtained by naturally cooling the vulcanizates down to room temperature.

5. Iisolation bearings samples: NR/IIR compound was prepared by the above method. Then the rubber compound sheets and the steel plate are overlapped in the mold for vulcanization. The size of the rubber bearing is $320 \times 420 \times 177 \mathrm{~mm}$. The curing temperature is $145^{\circ} \mathrm{C}$ and the curing time was determined by optimum cure time of $2 \mathrm{~mm}$ sheet.

\subsection{Characterization}

Molecular weight of IIBC was measured by gel permeation chromatography (GPC) on a Waters Breeze instrument equipped with three water columns (Steerage HT3_HT5_HT6E) by using tetrahydrofuran as the eluent $(1 \mathrm{ml} / \mathrm{min})$ and a Waters 2410 refractive index detector. A polystyrene standard was used for calibration.

Proton nuclear magnetic resonance $\left({ }^{1} \mathrm{H}\right.$ NMR $)$ spectra of IIBC with deuterated chloroform $\left(\mathrm{CDCl}_{3}\right)$ as the solvent was recorded on a Bruker AV400 spectrometer at room temperature.

Fourier transforms infrared spectroscopy (FTIR) absorption spectra of IIBC was acquired with a Tensor 27 IR spectrometer (Bruker Optics, Germany) in the wave-number range $4000-400 \mathrm{~cm}^{-1}(\mathrm{KBr}$ pellet technique) at a resolution of $4 \mathrm{~cm}^{-1}$.

Transmission electron microscopy (TEM, Tecnai G2 20 S-TWIN, FEI Co., Hong Kong) was employed to examine the morphology of the NR/IIR/IIBC composites. The samples for TEM observations were cryogenically cut with a glass knife on a ReichertJung Ultracut microtome (Leica Camera AG, Germany) and then stained by $\mathrm{OsO}_{4}$ for $10 \mathrm{~min}$.

The interphase structure and properties were studied using a nanomechanical mapping technique operated in PF-QNM mode on a Bruker Multi Mode AFM (Nanoscope IV Controller, Veeco Metrology). Before the observations, the samples were polished at $-130^{\circ} \mathrm{C}$ by using a cryo-ultramicrotome (Leica EM UC7, Germany).

The cure characteristics of the rubber compounds were studied with the help of a P3555B2 Disc Vulkameter (Beijing Huanfeng Chemical Machinery Trial Plant, Beijing, China) at $145^{\circ} \mathrm{C}$

The rubber process analyzer (RPA 2000, Alpha Technologies, USA) was employed to study the damping performance of the NR/IIR/IIBC composites. Dynamic strain sweeps were conducted by varying the strain ranges from 1 to $300 \%$ at a constant frequency of $1 \mathrm{~Hz}$ at $30^{\circ} \mathrm{C}$. Dynamic frequency sweeps were carried out from 0.1 to $7 \mathrm{~Hz}$ at a constant strain of $100 \%$ at $30^{\circ} \mathrm{C}$.

The dynamic loss factor $(\tan \delta)$ as a function of temperature were acquired with a VA3000 dynamic thermomechanical analysis (01 dB-Metravib, France) in the tension mode. The temperature was from -80 to $50{ }^{\circ} \mathrm{C}$, the heating rate was $3{ }^{\circ} \mathrm{C} / \mathrm{min}$, the frequency was $10 \mathrm{~Hz}$, and the strain amplitude was $0.3 \%$.

The static mechanical properties of the NR/IIR/IIBC composites were conducted according to ASTM (D638: Dumbbell-shaped) with a CMT4104 electronic tensile tester (Shenzhen SANS Test Machine Co., China) at a tensile rate of $500 \mathrm{~mm} / \mathrm{min}$. The dumbbell shaped samples $(25 \mathrm{~mm} \times 6 \mathrm{~mm} \times 2 \mathrm{~mm})$ were prepared according to ISO/DIS 37-1990.

The isolation bearings samples were tested on a pressure shear testing machine GX-235 (YJZ-30000, Petroleum and Chemical Industry General Quality 
Supervision Center for Rubber and Chemicals, China) that could simulate the actual situation during an earthquake (The machine photos are shown in Figure $6 \mathrm{a}-6 \mathrm{c})$. The temperature was $23^{\circ} \mathrm{C}$, the humidity was 22 , the loading waveform was sine wave, and the loading frequency was $0.01 \mathrm{~Hz}$. The machine first did the vertical compression test and then did the shear test which are both qualified.

\section{Results and discussion}

\subsection{Characterization of isobutylene-isoprene block copolymer}

FTIR spectrum was obtained to characterize the molecular structure of the IIBC, as shown in Figure 1. The absorption peak at $3185 \mathrm{~cm}^{-1}$ may be attributed to the vibration of unsaturated hydrogen. The peaks at 2953 and $2924 \mathrm{~cm}^{-1}$ are assigned to the asymmetric stretching vibration of $-\mathrm{CH}_{3}$ and $-\mathrm{CH}_{2}$ group which comes from the isobutylene and isoprene segments and the peak at $2851 \mathrm{~cm}^{-1}$ is assigned to the symmetric stretching vibration of $-\mathrm{CH}_{3}$ and $-\mathrm{CH}$ group. The peak at $1633 \mathrm{~cm}^{-1}$ is assigned to the stretching vibration of $-\mathrm{C}=\mathrm{C}$ - group, indicating the

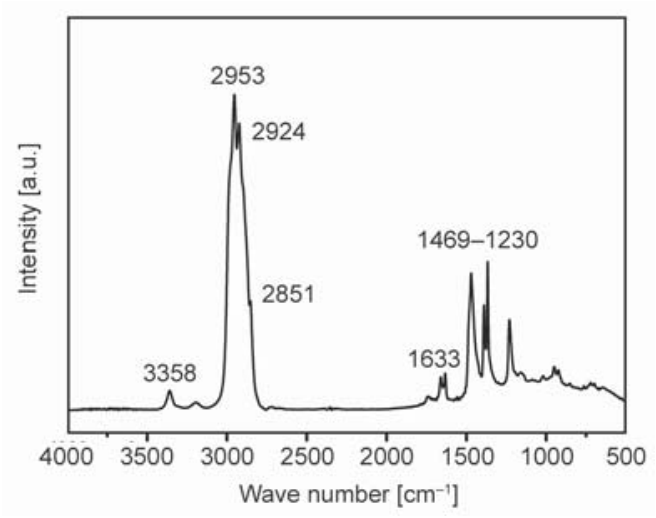

Figure 1. FTIR spectra of IIBC.

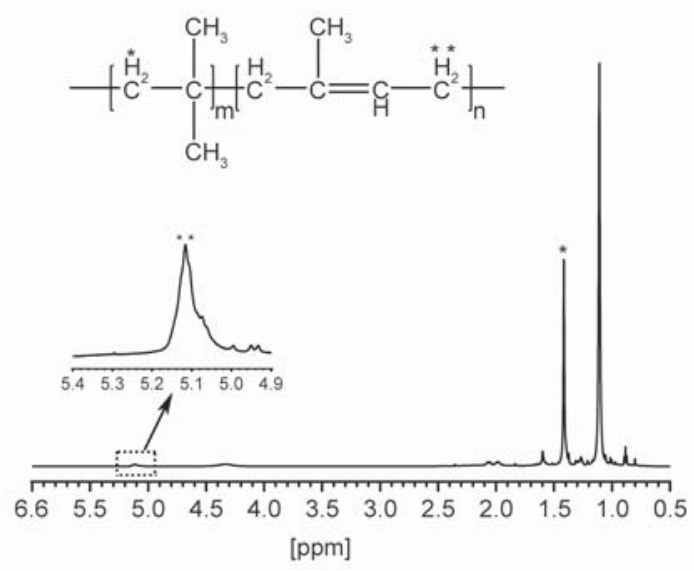

Figure 2. Molecular formula and H NMR nuclear spectra of IIBC. existence of the isoprene segments [17]. In addition, the absorption zone at $1230 \sim 1469 \mathrm{~cm}^{-1}$ results from the stretching of benzene which introduced by the initiator. The FTIR results are well in agreement with NMR results mentioned later.

Figure 2 shows the molecular formula and the H NMR nuclear spectra of IIBC. We can quantitatively analyze the relative content of different components in the block copolymers by NMR. The highest peak at $1.1 \mathrm{ppm}$ can be assigned to the methyl protons $\left(-\mathrm{CH}_{3}\right)$ of the polyisobutylene units of IIBC. The peak at $1.41 \mathrm{ppm}$ is assigned to the hydrogen of methylene $\left(-\mathrm{CH}_{2}-\right)$ of polyisobutylene segments, and every two moles of hydrogen correspond to one mole of isobutylene. The peak at $5.12 \mathrm{ppm}$ corresponds to the hydrogen attached to the allyl carbon in isoprene segment, and every one mole of the hydrogen corresponds to one mole of isoprene [18]. We set the peak intensity at 5.12 to $1\left(S_{5.12}=1\right)$, and the corresponding peak intensity at 1.41 is $11.78\left(S_{1.41}=11.78\right)$. Therefore, we can get the content of isoprene in IIBC by Equation (1):

$X_{\mathrm{IP}}=\frac{\mathrm{IP}}{\mathrm{IB}+\mathrm{IP}}=\frac{S_{5.12}}{\frac{S_{1.41}}{2}+S_{5.12}}=\frac{1}{\frac{11.78}{2}+1}=14.5 \%$

where $X_{\text {IP }}$ means the content of isoprene in IIBC, IP and IB mean isoprene and isobutylene respectively. Compared with IIR, the content of isoprene in IIBC has been increased by more than $10 \%$. This is expected to make IIBC a promising compatibilizer for the NR/IIR blend.

Molecular weights of the IIBC were measured by gel permeation chromatography (GPC), and the measured curve is shown in Figure 3. As can be seen, the

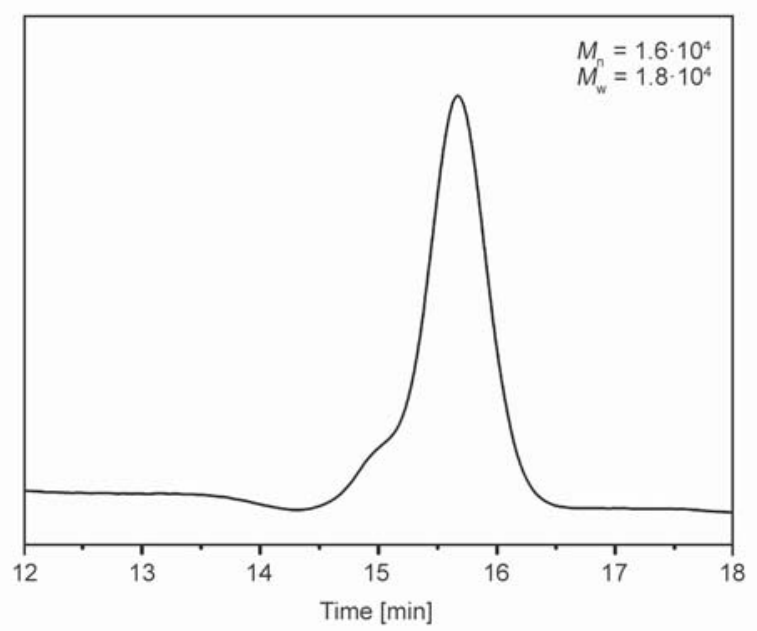

Figure 3. GPC curve of IIBC. 
number-average molecular weight $(\mathrm{Mn})$ of the IIBC is $1.6 \cdot 10^{4}$ and the weight-average molecular weight $\left(M_{\mathrm{w}}\right)$ is $1.8 \cdot 10^{4}$. The molecular weight is low. Therefore, to prevent the reduction of mechanical properties, it is not suitable to add too much IIBC to the rubber blend.

\subsection{Microscopic phase morphology of NR/IIR blends}

The effects of IIBC as a compatibilizer on the phase morphology of NR/IIR blend were characterized by TEM and AFM. TEM images (Figure 4) show that NR/IIR blends has a typical sea island morphology, where IIR spherical island (lighter regions) with several micron sizes are dispersed in the NR continuous phase (darker regions). In addition, a clear and sharp boundary between the two phases in NR/IIR (80/20) blend indicates that NR and IIR are highly immiscible. By adding $4 \mathrm{phr}$ of IIBC, interface between NR and IIR becomes fuzzy, indicating an improved interfacial bonding. This is ascribed to the compatibilizing effect of IIBC. Due to containing the polyisoprene segment and the polyisobutylene segment, IIBC

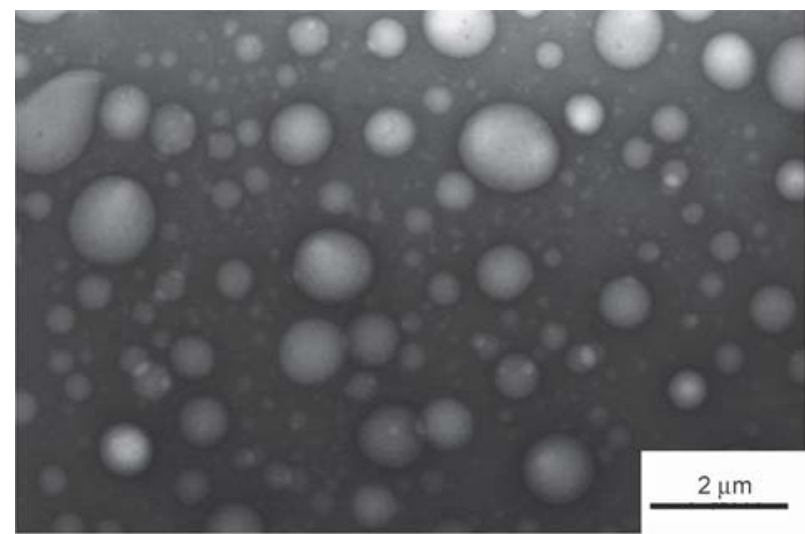

a)

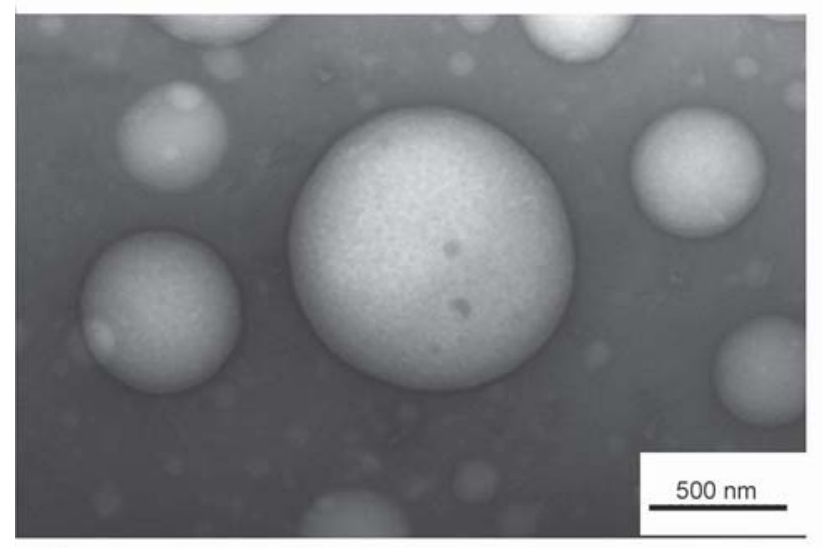

c)

Figure 4. Comparison between morphology of NR/IIR blend compatibilized by IIBC and non-compatibilized one. TEM micrographs at different magnification of (a), (c) NR/IIR (80/20) blend and (b), (d) NR/IIR/IIBC (80/20/4) blend. simultaneously has good affinity with NR and IIR; therefore, it can infiltrate and then attach the two phase at the interface during the blending procedure. Particularly worth mentioning is the shape change of the IIR phases. Without IIBC, the IIR phases are mostly of ball shape. When adding $4 \mathrm{phr}$ of IIBC, we can see the IIR phase exhibit irregular structure. It is mainly because of the improved stress transfer at the interface. The strong interfacial bonding enables the shear force applied on the continuous phase to be effectively transferred to the dispersed phase, causing it to become an irregular shape during the manufacturing process.

In recent years, the peak force quantitative nanomechanical mapping (PF-QNM) technique, based on the principle of AFM peak force tapping mode, was developed to characterize the interphase of polymer composites [19-21]. Compared with conventional tapping mode, PF-QNM mode is able to detect more accurately the mechanical interaction and thickness of the interface [22]. Based on this efficient technique, AFM was used to analyze the modulus change of rubber blends with respect to the distance along

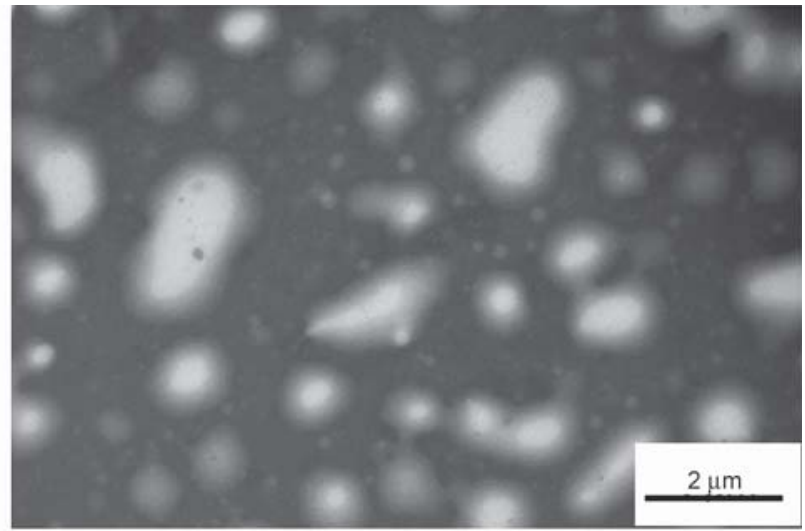

b)

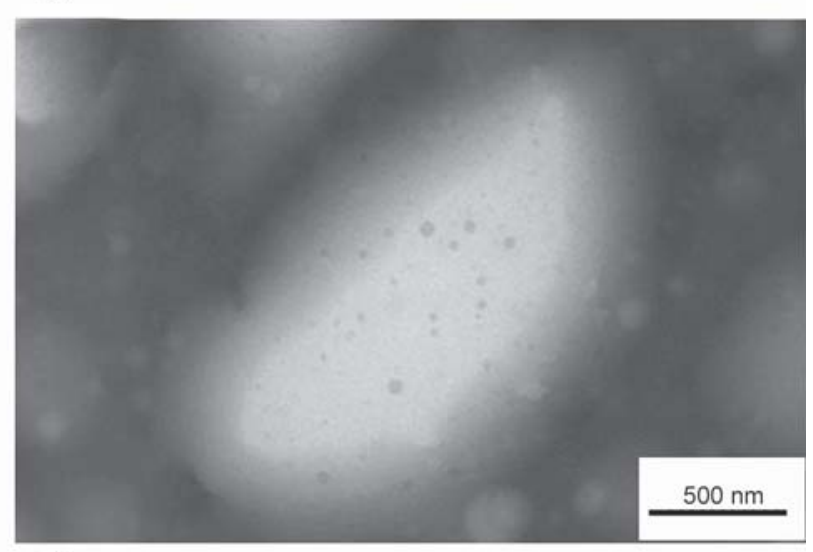

d) 

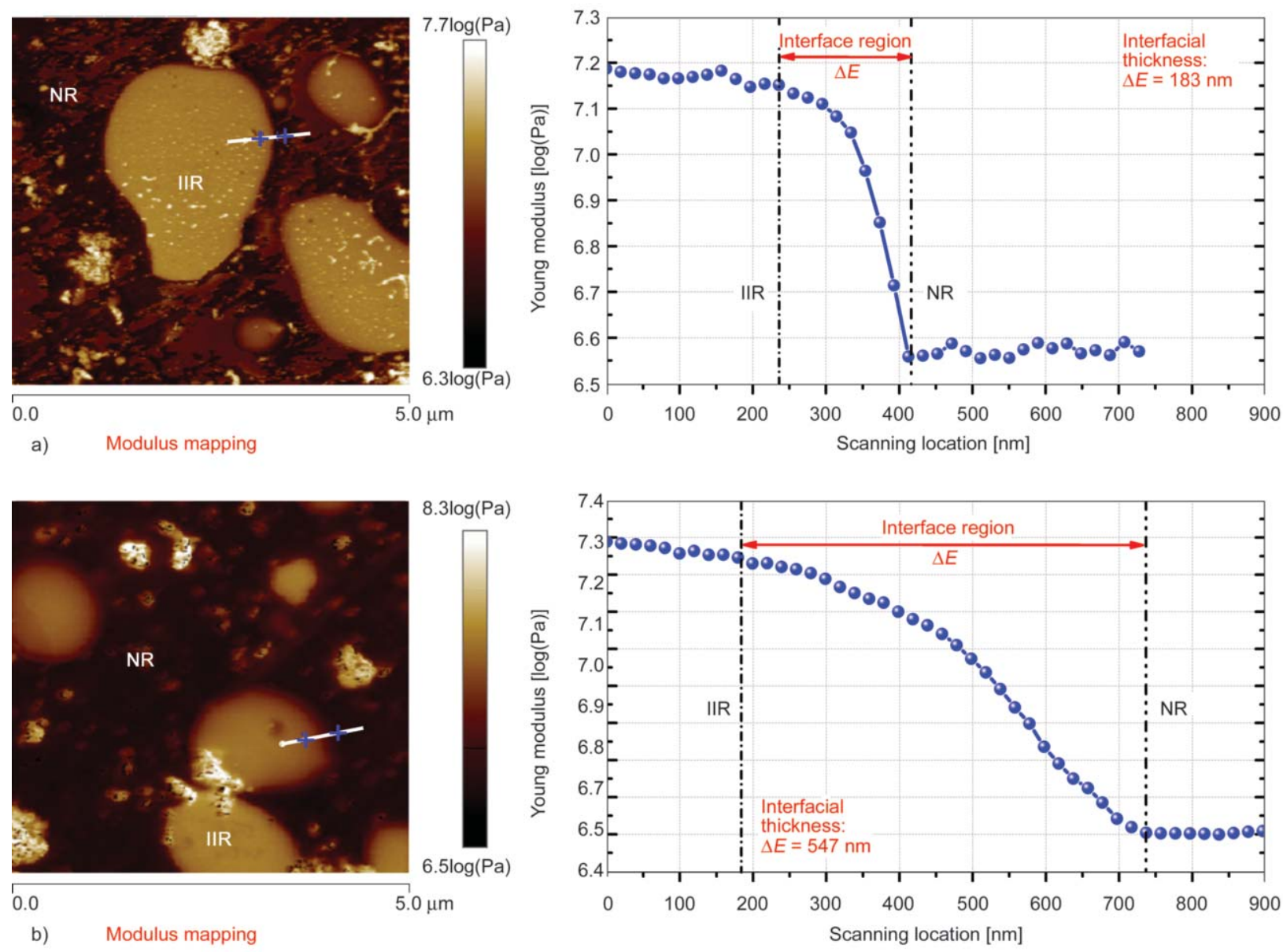

Figure 5. Representative AFM Young's modulus images of (a) NR/IIR (80/20), (b) NR/IIR/IIBC (80/20/4) blends and their corresponding modulus-scanning location curve to represent the interfacial thickness between NR and IIR.

the interface to quantitatively reflect the interfacial thickness as shown in Figure 5. The similar grossphase separated morphology was clearly seen through the AFM modulus images, and we also note that the modulus of non-compatibilizd NR/IIR blends changes abruptly at the interface, revealing an extremely weak interfacial adhesion. By adding $4 \mathrm{phr}$ of IIBC, the change of interface modulus becomes smooth, and the blend presents a substantial increase of interfacial thickness (from 183 to $547 \mathrm{~nm}$ ). This further confirms IIBC is an excellent compatilizer to improve the interfacial bonding strength of NR/NBR blend.

\subsection{Cure characteristics and mechanical properties of $\mathrm{NR} / \mathrm{IIR}$ blends}

The curing curves and characteristics of the NR/IIR blends compatibilized by different contents of IIBC are shown in Figure 6 and Table 2, respectively. The minimum torques $M_{\mathrm{L}}$ decreases with the increase of IIBC content, and this may be due to the plasticization of low molecular weight IIBC. Additionally, the

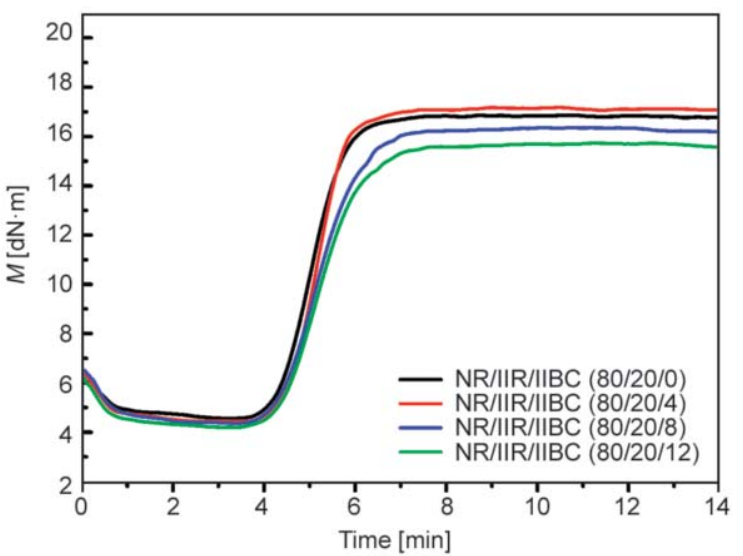

Figure 6. Rheographs of NR/IIR blends at $145^{\circ} \mathrm{C}$ with various contents $(0,4,8$ and $12 \mathrm{phr})$ of IIBC.

maximum torque $M_{\mathrm{H}}$ as well as a torque difference $(\Delta M)$ slightly increase with adding $4 \mathrm{phr}$ of IIBC, which may be attributed to the improved interface bonding. However, further addition of IIBC decreases the $M_{\mathrm{H}}$ and $\Delta M$, indicating a decrease in crosslink density of the blends. That might be because the ratios of NR to whole rubber compound decreased with 
Table 2. Cure characteristics of NR/IIR composites.

\begin{tabular}{|c|c|c|c|c|c|}
\hline Content of IIBC & $\begin{array}{c}\text { Maximum torque, } \boldsymbol{M}_{\mathbf{H}} \\
{[\mathbf{d N} \cdot \mathbf{m}]}\end{array}$ & $\begin{array}{c}\text { Minimum torque, } \boldsymbol{M}_{\mathbf{L}} \\
{[\mathbf{d N} \cdot \mathbf{m}]}\end{array}$ & $\begin{array}{c}\boldsymbol{\Delta} \boldsymbol{M}=\boldsymbol{M H}-\boldsymbol{M}_{\mathbf{L}} \\
{[\mathbf{d N} \cdot \mathbf{m}]}\end{array}$ & $\begin{array}{c}\mathbf{S} \text { corch time, } \boldsymbol{T}_{\mathbf{1 0}} \\
{[\mathbf{m i n}]}\end{array}$ & $\begin{array}{c}\text { Optimum cure time, } \boldsymbol{T}_{\mathbf{9 0}} \\
{[\mathbf{m i n}]}\end{array}$ \\
\hline $0 \mathrm{phr}$ & 16.83 & 4.57 & 12.26 & 4.3 & 6.6 \\
\hline $4 \mathrm{phr}$ & 17.17 & 4.44 & 12.73 & 4.4 & 6.8 \\
\hline $8 \mathrm{phr}$ & 16.27 & 4.37 & 11.90 & 4.4 & 6.8 \\
\hline $12 \mathrm{phr}$ & 15.63 & 4.21 & 11.42 & 4.3 & 6.6 \\
\hline
\end{tabular}

adding too much IIBC, leading to a decrease in vulcanization efficiency. The Table 2 also shows that the addition of IIBC has no significant effect on the scorch and cure times.

The effect of IIBC as a compatibilizer on the mechanical performance of the NR/IIR blends is presented through stress-strain curves in Figure 7 . The tensile strength and the modulus (50-400\%) both increase with addition of $4 \mathrm{phr}$ of IIBC owing to its remarkable compatibilizing effect. However, the tensile strength decreases with adding more compatibilizer, which may be caused by the decreased crosslink density. Table 3 shows the data of static mechanical properties of NR/IIR blends. As can be seen, the tensile strength increased from 19.1 to $21.6 \mathrm{MPa}$ when adding $4 \mathrm{phr}$ of IIBC. The Shore A hardness increased first and then decreased with further increase content of IIBC, which is consistent with trends of

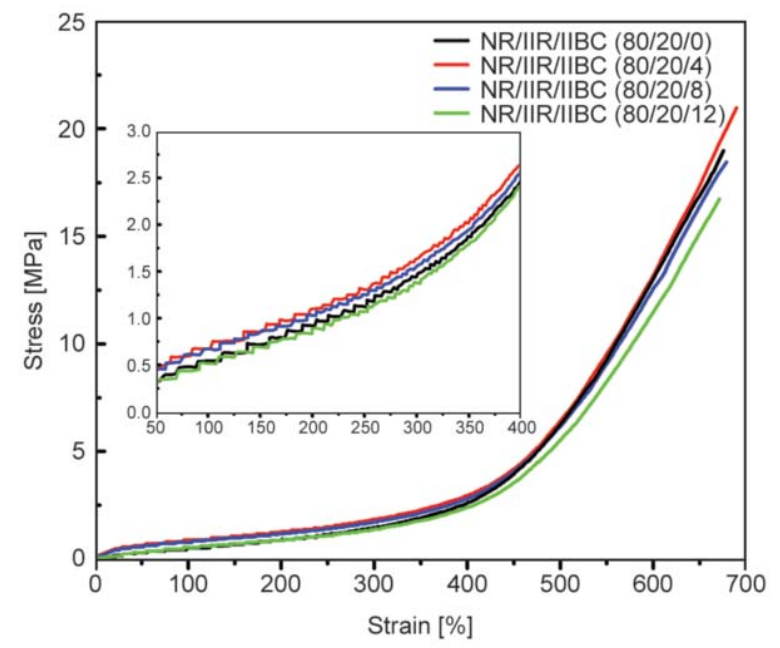

Figure 7. Stress-strain curves of NR/IIR blends compatibilized by different contents of IIBC. the modulus. The appropriately increased modulus will benefit the improvement of stiffness and ability to resist damage of the final isolation bearing products [23].

\subsection{Dynamic properties of NR/IIR blends}

$\operatorname{Tan} \delta$ values of isolation rubber bearings are required to be higher than 0.1 (equivalent damping ratio of $10 \%$ ) in $0.2 \sim 5 \mathrm{~Hz}$ frequency range and $10 \sim 200 \%$ strain range, according to the ISO standard [24]. The $\tan \delta$ reflects the internal friction; the stronger the internal friction, the higher the $\tan \delta$ value and the better the damping performance [25]. RPA tests were conducted to investigate the $\tan \delta$ variation of NR/IIR blends under dynamic shear strain and frequency condition. Figures $8 \mathrm{a}, 8 \mathrm{~b}$ shows the loss factor $(\tan \delta)$ as a function of strain and frequency for NR/IIR blends with different IIBC contents. The $\tan \delta$ values are higher than 0.1 in the frequency range $0.2 \sim 5 \mathrm{~Hz}$ and the strain range $10 \sim 200 \%$ for the NR/IIR blends compatibilized by 8 or $12 \mathrm{phr}$ of IIBC, which far exceed ISO standards. But the non-compatibilized one cannot meet the standards in the whole frequency range and almost the whole strain range. For the NR/IIR blends compatibilized by 4 phr of IIBC, its $\tan \delta$ value is higher than 0.1 in the whole frequency range and the strain range $50-200 \%$, while the value is less than 0.1 in the strain range $10 \sim 50 \%$. The $\tan \delta$ values of both strain sweep and frequency sweep greatly increase with increasing content of IIBC. This result can be explained by a model illustrated in Figure $8 \mathrm{~d}$. When subjected to the external shear forces, compared to the NR/IIR blend, compatibilized NR/IIR/IIBC blends could very easily transfer

Table 3. Static mechanical properties of NR/IIR composites.

\begin{tabular}{|c|c|c|c|c|c|}
\hline Content of IIBC & $\begin{array}{c}\text { Tensile strength } \\
{[\text { MPa] }}\end{array}$ & Shore A hardness & $\begin{array}{c}\mathbf{1 0 0 \%} \text { modulus } \\
{[\mathbf{M P a}]}\end{array}$ & $\begin{array}{c}\mathbf{3 0 0 \%} \text { modulus } \\
{[\mathbf{M P a}]}\end{array}$ & $\begin{array}{c}\text { Elongation at break } \\
{[\%]}\end{array}$ \\
\hline $0 \mathrm{phr}$ & $19.1 \pm 0.9$ & $39 \pm 0.5$ & $0.54 \pm 0.05$ & $1.41 \pm 0.10$ & $677 \pm 9$ \\
\hline $4 \mathrm{phr}$ & $21.6 \pm 0.6$ & $41 \pm 0.7$ & $0.65 \pm 0.04$ & $1.57 \pm 0.07$ & $690 \pm 7$ \\
\hline $8 \mathrm{phr}$ & $18.6 \pm 0.8$ & $40 \pm 0.4$ & $0.61 \pm 0.05$ & $1.54 \pm 0.09$ & $680 \pm 10$ \\
\hline $12 \mathrm{phr}$ & $16.7 \pm 1.1$ & $37 \pm 0.7$ & $0.52 \pm 0.08$ & $1.40 \pm 0.12$ & $669 \pm 11$ \\
\hline
\end{tabular}



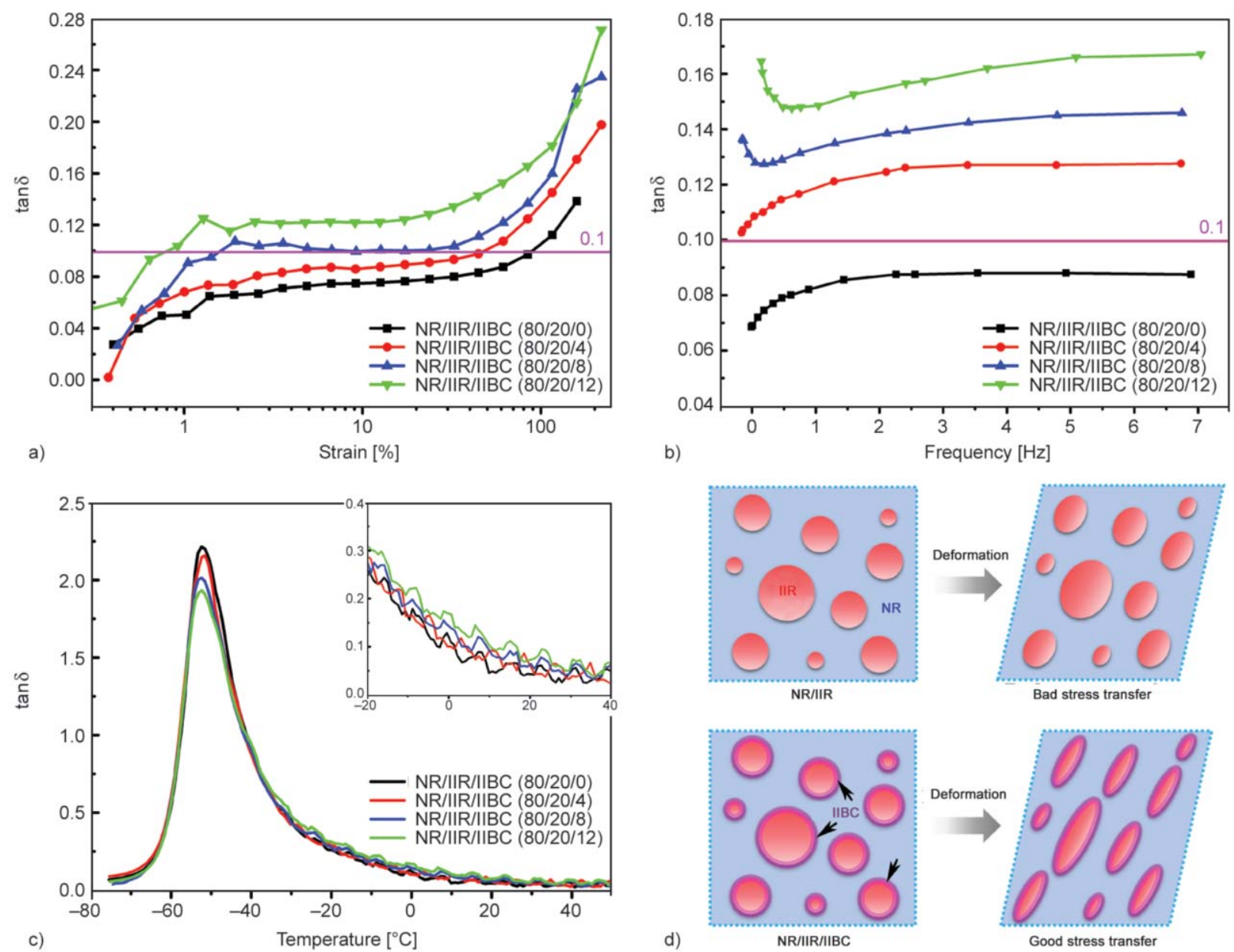

Figure 8. Comparison and analysis of the damping properties of NR/IIR blends with different content of IIBC. (a) Loss factor-dynamic strain curves, (b) loss factor-dynamic frequency curves, and (c) loss factor-temperature curves of NR/IIR blends with different content of IIBC (d) design concept of high damping model.

the external forces to the IIR damping phase through the strengthened interface, causing a larger deformation of the damping phase and more desirable energy dissipation. Overall, the damping performance of NR/IIR blends can be improved by adjusting the IIBC contents, indicating the good damping performance of NR/IIR/IIBC blends for potential applications in isolation rubber bearings.

Figure $8 \mathrm{c}$ shows the temperature dependence of the $\tan \delta$ for the NR/IIR blends. For each curve, only one $\tan \delta$ peak is observed, which is ascribed to the similar glass transition temperature between NR and IIR. With increasing IIBC content, the height of the $\tan \delta$ peak decreases, but the height of the curve in the temperature range $-30 \sim 40{ }^{\circ} \mathrm{C}$ increases gradually. The NR/IIR/IIBC blends show a broader efficient damping temperature range around room temperature than the NR/IIR blend.

\subsection{Test of isolation bearings samples on a pressure shear testing machine}

To further evaluate the properties of the blends, we prepared bearings samples of NR compound and the new NR/IIR compound, and test them on a pressure shear testing machine GX-235 that could simulate the actual situation during an earthquake. Figure $9 \mathrm{a}-$ 9c shows the machine, isolation bearings samples, and the testing process. The test results are listed in the Table 4. As we can see, the NR compound as a control sample cannot meet the standard (required in Chinese national standards GB20688.3-2006). Compared with the unqualified NR compound, the new compound has improved horizontal equivalent stiffness and equivalent damping ratio which are both qualified. Moreover, although the vertical stiffness of the new compound is slightly lower than that of NR compound, it is still within the standard range. 

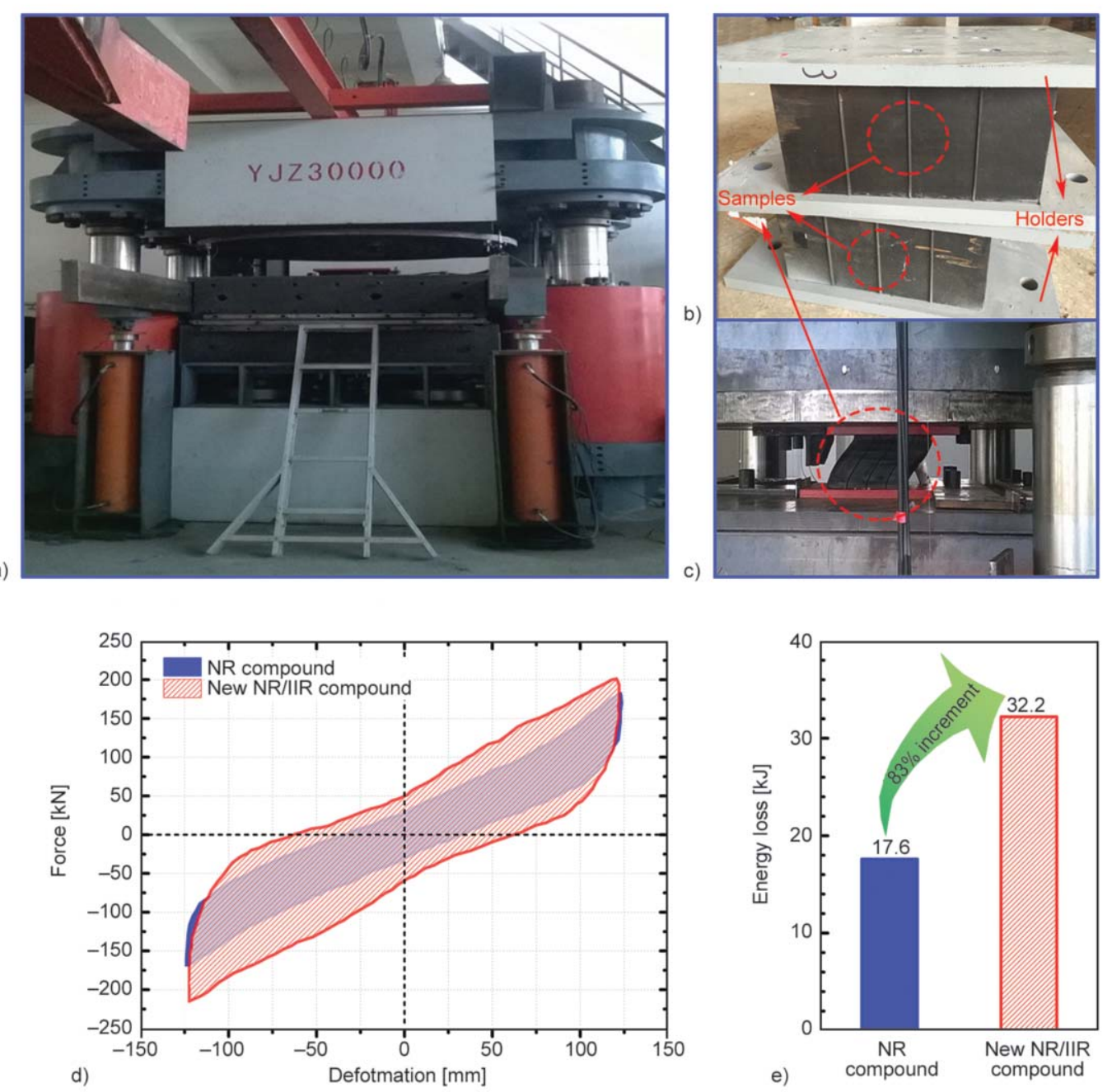

Figure 9. (a) Picture of the pressure shear testing machine GX-235, (b) the NR and the new NR/IIR bearing samples we prepared, (c) the bearing sample shear tested on the machine, (d) hysteretic curves of the NR and the new NR/IIR bearing samples, (e) area of hysteretic loop (for one cycle) of the NR and the new NR/IIR bearing samples.

Table 4. Test results of rubber isolation bearing samples.

\begin{tabular}{|ll|c|c|c|}
\hline \multicolumn{2}{|c|}{ Performances } & Standard & NR compound & New NR/IIR compound \\
\hline Vertical stiffness & {$[\mathrm{kN} / \mathrm{mm}]$} & $875 \times(1 \pm 30 \%)$ & 857 & 810 \\
\hline Horizontal equivalent stiffness & {$[\mathrm{kN} / \mathrm{mm}]$} & $1.7 \times(1 \pm 15 \%)$ & 1.4 (unqualified) & 1.9 \\
\hline Equivalent damping ratio & {$[\%]$} & $\geq 15$ & 13 (unqualified) & 16 \\
\hline
\end{tabular}

Figure 9d shows the shear force-deformation curves of the bearing samples. The area of the hysteresis loop can reflect the energy dissipation of the bearing samples during shear deformation [26]. The new bearing sample obviously has a larger area of the hysteresis loop. Figure 9e reveals that the energy loss (for one cycle) of the new bearing sample is $83 \%$ higher than that of the NR sample. This means that when the isolation bearings undergo the equivalent earthquake energy, the new one is more effective in consuming the earthquake energy.

\section{Conclusions}

The NR/IIR blends compatibilized by IIBC were successfully prepared in this study. The TEM and AFM revealed that the NR/IIR blends have typical incompatible sea island biphase structure. The compatibility of NR/IIR blends were significantly improved with the addition of IIBC. The tensile strength of blend increased from 19.1 to $21.6 \mathrm{MPa}$ when $4 \mathrm{phr}$ of IIBC was added. The IIBC could significantly improve the damping factor and the dissipation efficiency of the blends, which may be attributed to the improved stress 
transfer at the interface. Therefore, the NR/IIR/IIBC blends are expected to be potential materials for high damping isolation rubber bearings.

\section{Acknowledgements}

The authors sincerely appreciate the financial supports from the Natural Science Foundation of China (Grant No. 51320105012).

\section{References}

[1] Reggio A., Angelis M. D.: Combined primary-secondary system approach to the design of an equipment isolation system with high-damping rubber bearings. Journal of Sound and Vibration, 333, 2386-2403 (2014). https://doi.org/10.1016/j.jsv.2013.12.006

[2] Steelman J. S., Fahnestock L. A., Filipov E. T., LaFave J. M., Hajjar J. F., Foutch D. A.: Shear and friction response of nonseismic laminated elastomeric bridge bearings subject to seismic demands. Journal of Bridge Engineering, 18, 612-623 (2013).

https://doi.org/10.1061/(ASCE)BE.1943-5592.0000406

[3] Zordan T., Liu T., Briseghella B., Zhang Q.: Improved equivalent viscous damping model for base-isolated structures with lead rubber bearings. Engineering Structures, 75, 340-352 (2014).

https://doi.org/10.1016/j.engstruct.2014.05.044

[4] Wang W., Zhao D., Yang J., Nishi T., Ito K., Zhao X., Zhang L.: Novel slide-ring material/natural rubber composites with high damping property. Scientific Report, 6, 22810/1-22810/13 (2016).

https://doi.org/10.1038/srep22810

[5] Choun Y-S., Park J., Choi I-K.: Effects of mechanical property variability in lead rubber bearings on the response of seismic isolation system for different ground motions. Nuclear Engineering and Technology, 46, 605-618 (2014).

https://doi.org/10.5516/NET.09.2014.718

[6] Zhao X., Niu K., Xu Y., Peng Z., Jia L., Hui D., Zhang L.: Morphology and performance of NR/NBR/ENR ternary rubber composites. Composites Part B: Engineering, 107, 106-112 (2016).

https://doi.org/10.1016/j.compositesb.2016.09.073

[7] Brüning K., Schneider K., Roth S. V., Heinrich G.: Kinetics of strain-induced crystallization in natural rubber studied by WAXD: Dynamic and impact tensile experiments. Macromolecules, 45, 7914-7919 (2012).

https://doi.org/10.1021/ma3011476

[8] Weng G., Huang G., Qu L., Nie Y., Wu J.: Large-scale orientation in a vulcanized stretched natural rubber network: Proved by in situ synchrotron X-ray diffraction characterization. Journal of Physical Chemistry B, 114, 7179-7188 (2010).

https://doi.org/10.1021/jp100920g
[9] Toki S., Sics I., Ran S., Liu L., Hsiao B. S., Murakami S., Senoo K., Kohjiya S.: New insights into structural development in natural rubber during uniaxial deformation by in situ synchrotron X-ray diffraction. Macromolecules, 35, 67-77 (2002).

https://doi.org/10.1021/ma0205921

[10] Qin R., Huang R., Lu X.: Use of gradient laminating to prepare NR/ENR composites with excellent damping performance. Materials and Design, 149, 43-50 (2018). https://doi.org/10.1016/j.matdes.2018.03.063

[11] Burtscher S. L., Dorfmann A.: Compression and shear tests of anisotropic high damping rubber bearings. Engineering Structures, 26, 1979-1991 (2004).

https://doi.org/10.1016/j.engstruct.2004.07.014

[12] Liao F-S., Su A-C., Hsu T-C. J.: Damping behaviour of dynamically cured butyl rubber/polypropylene blends. Polymer, 35, 2579-2586 (1994).

https://doi.org/10.1016/0032-3861(94)90382-4

[13] Wang Y. Q., Peng Z., Zhong J. P., Xu K., Yang C. J., Luo Y. Y., Li P. W.: Damping performance of CB filled NR/ENR, NR/BR and NR/IIR compounds. Applied Mechanics and Materials, 716-717, 70-73 (2014).

https://doi.org/10.4028/www.scientific.net/AMM.716-717.70

[14] Wang J., Zhao X., Wang W., Geng X., Zhang L., Guo B., Nishi T., Hu G-H.: Significantly improving strength and damping performance of nitrile rubber via incorporating sliding graft copolymer. Industrial and Engineering Chemistry Research, 57, 16692-16700 (2018).

https://doi.org/10.1021/acs.iecr.8b03871

[15] Qiao B., Zhao X., Yue D., Zhang L., Wu S.: A combined experiment and molecular dynamics simulation study of hydrogen bonds and free volume in nitrile-butadiene rubber/hindered phenol damping mixtures. Journal of Materials Chemistry, 22, 12339-12348 (2012). https://doi.org/10.1039/c2jm31716h

[16] Kaneko H., Inoue K., Tominaga Y., Asai S., Sumita M.: Damping performance of polymer blend/organic filler hybrid materials with selective compatibility. Materials Letters, 52, 96-99 (2002).

https://doi.org/10.1016/s0167-577x(01)00373-1

[17] Rehner J., Gray P.: Determination of unsaturation in butyl rubber. Rubber Chemistry and Technology, 18, 887-895 (1945). https://doi.org/10.5254/1.3546788

[18] Chu C. Y., Vukov R.: Determination of the structure of butyl rubber by NMR spectroscopy. Macromolecules, 18, 1423-1430 (1985). https://doi.org/10.1021/ma00149a012

[19] Fery A., Krausch G., Papastavrou G.: Probing soft matter by AFM. Polymer, 102, 315-316 (2016). https://doi.org/10.1016/j.polymer.2016.08.080

[20] Cheng X., Putz K. W., Wood C. D., Brinson L. C.: Characterization of local elastic modulus in confined polymer films via AFM indentation. Macromolecular Rapid Communication, 36, 391-397 (2015). https://doi.org/10.1002/marc.201400487 
[21] Martinez-Tong D. E., Najar A. S., Soccio M., Nogales A., Bitinis N., López-Manchado M. A., Ezquerra T. A.: Quantitative mapping of mechanical properties in polylactic acid/natural rubber/organoclay bionanocomposites as revealed by nanoindentation with atomic force microscopy. Composites Science and Technology, 104, 34-39 (2014).

https://doi.org/10.1016/j.compscitech.2014.08.030

[22] Ning N., Mi T., Chu G., Zhang L-Q., Liu L., Tian M., Yu H-T., Lu Y-L.: A quantitative approach to study the interface of carbon nanotubes/elastomer nanocomposites. European Polymer Journal, 102, 10-18 (2018). https://doi.org/10.1016/j.eurpolymj.2018.03.007

[23] Nishi T., Murota N.: Elastomeric seismic-protection isolators for buildings and bridges. Chinese Journal of Polymer Science, 31, 50-57 (2013).

https://doi.org/10.1007/s10118-013-1217-8
[24] Murota N., Kelly J. M., Fuller K., Zhou F. L., Nishi T., Yoshizawa T., Suduo C., Yazaki F.: New international standard for elastomeric seismic-protection isolators. in 'Fifth National Seismic Conference on Bridges and Highways, San Francisco, USA' p11 (2006).

[25] Zhao X-Y., Xiang P., Tian M., Fong H., Jin R., Zhang L-Q.: Nitrile butadiene rubber/hindered phenol nanocomposites with improved strength and high damping performance. Polymer, 48, 6056-6063 (2007). https://doi.org/10.1016/j.polymer.2007.08.011

[26] Davies D. M., McCallion H.: Effect of previous stressstrain history on the dynamic hysteresis loop for rubber in compression. Nature, 173, 262-263 (1954).

https://doi.org/10.1038/173262a0 